\title{
Bone marrow mononuclear cells reduce seizure frequency and improve cognitive outcome in chronic epileptic rats
}

\author{
Gianina Teribele Venturin ${ }^{\mathrm{a}, \mathrm{b}}$, Samuel Greggio ${ }^{\mathrm{b}}$, Daniel Rodrigo Marinowic ${ }^{\mathrm{c}}$, Gabriele Zanirati ${ }^{\mathrm{b}}$, \\ Martín Cammarota ${ }^{\mathrm{d}}$, Denise Cantarelli Machado ${ }^{\mathrm{c}}$, Jaderson Costa DaCosta ${ }^{\mathrm{b}, *}$ \\ a Programa de Pós-Graduação em Neurociências, Universidade Federal do Rio Grande do Sul, Porto Alegre, RS, Brazil

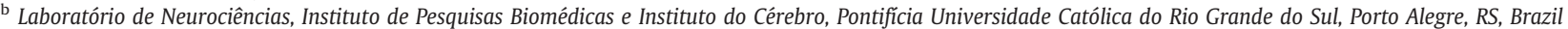 \\ c Laboratório de Terapia Celular, Instituto de Pesquisas Biomédicas e Instituto do Cérebro, Pontifícia Universidade Católica do Rio Grande do Sul, Porto Alegre, RS, Brazil \\ d Centro de Memória, Instituto de Pesquisas Biomédicas e Instituto do Cérebro, Pontificia Universidade Católica do Rio Grande do Sul, Porto Alegre, RS, Brazil
}

\section{A R T I C L E I N F O}

\section{Article history:}

Received 25 January 2011

Accepted 3 June 2011

\section{Keywords:}

Temporal lobe epilepsy

Seizures

Bone marrow stem cells

Cognition

\begin{abstract}
A B S T R A C T
Aims: Epilepsy affects $0.5-1 \%$ of the world's population, and approximately a third of these patients are refractory to current medication. Given their ability to proliferate, differentiate and regenerate tissues, stem cells could restore neural circuits lost during the course of the disease and reestablish the physiological excitability of neurons. This study verified the therapeutic potential of bone marrow mononuclear cells (BMMCs) on seizure control and cognitive impairment caused by experimentally induced epilepsy. Main methods: Status epilepticus (SE) was induced by lithium-pilocarpine injection and controlled with diazepam 90 min after SE onset. Lithium-pilocarpine-treated rats were intravenously transplanted 22 days after SE with BMMCs obtained from enhanced green fluorescent protein (eGFP) transgenic C57BL/6 mice. Control epileptic animals were given an equivalent volume of saline or fibroblast injections. Animals were video-monitored for the presence of spontaneous recurrent seizures prior to and following the cell administration procedure. In addition, rats underwent cognitive evaluation using a Morris water maze. Key findings: Our data show that BMMCs reduced the frequency of seizures and improved the learning and long-term spatial memory impairments of epileptic rats. EGFP-positive cells were detected in the brains of transplanted animals by PCR analysis.

Significance: The positive behavioral effects observed in our study indicate that BMMCs could represent a promising therapeutic option in the management of chronic temporal lobe epilepsy.
\end{abstract}

(c) 2011 Elsevier Inc. All rights reserved.

\section{Introduction}

Epilepsy is a chronic neurological disorder that affects $0.5-1 \%$ of the population worldwide (Engel, 2001; Sander and Shorvon, 1996). The response to therapy in newly diagnosed cases is generally good, but up to $30 \%$ of patients cannot achieve acceptable seizure control despite adequate trials with potentially effective antiepileptic agents (Loscher, 2002). In addition, there is the risk of a large number of adverse effects, and surgical treatment is limited due to possible brain function impairments.

Temporal lobe epilepsy (TLE) is the most frequent refractory form of epilepsy in adult patients (Engel, 2001). Patients with TLE often show extensive cell loss in temporal brain areas, especially in the hippocampus; this characterizes mesial temporal sclerosis (MTS)-

\footnotetext{
* Corresponding author at: Laboratório de Neurociências, Instituto do Cérebro (Inscer), Pontifícia Universidade Católica do Rio Grande do Sul (PUCRS), Avenida Ipiranga 6690, Jardim Botânico, Prédio 60, $2^{\circ}$ andar, sala 07, CEP 90619-900, Porto Alegre, RS, Brazil. Tel.: + 5551 33203250; fax: + 555133203312 .

E-mail address: jcc@pucrs.br (J.C. DaCosta).
}

associated TLE. The main physiopathological findings observed in MTS are neuronal loss, reactive gliosis, mossy fiber sprouting, dendritic injury and neurogenesis (Babb et al., 1991; Blumcke et al., 1999). Several clinical observations suggest that epilepsy is more complex than recurrent seizures alone and that progressive cognitive impairment should be included in the sequelae of refractory TLE, particularly when associated with hippocampal sclerosis (Hermann et al., 2002; Hermann et al., 2006; Oyegbile et al., 2006; Oyegbile et al., 2004).

Intense neuronal loss is intimately related to EMT and chronic epileptic activity (Blumcke et al., 1999; Blumcke et al., 1996). Thus, the replacement of cells lost during the course of disease or the replacement of physiological mediators produced by the cells may represent effective strategies in the treatment of refractory epilepsy. Transplanted stem cells could exert their effects not only by transdifferentiating but also by other means such as cell fusion, the release of trophic factors or cytokines, or even by activating endogenous neural stem cells (Terada et al., 2002).

A number of cell transplantation strategies have been studied in experimental models of epilepsy (Carpentino et al., 2008; Chu et al., 2004; Gernert et al., 2002; Hattiangady et al., 2008; Huber et al., 2001; 
Jing et al., 2009; Li et al., 2009b; Ruschenschmidt et al., 2005; Shen et al., 2010; Zaman et al., 2000). Recently, Costa-Ferro et al. (2010) showed that bone marrow mononuclear cells (BMMCs) can prevent the development of chronic seizures, reduce neuronal loss, and influence the reorganization of the hippocampal network in the acute phase of experimental epilepsy.

However, the therapeutic potential of BMMCs in chronic epileptic disorders remains unknown. To explore this possibility, we transplanted lithium-pilocarpine-treated rats with the mononuclear cell fraction of the bone marrow of enhanced green fluorescent protein (eGFP) transgenic C57BL/6 mice and investigated its effects on seizure frequency and duration as well as cognitive outcome in chronic epilepsy.

\section{Material and methods}

\section{Animals}

Seventy male Wistar rats (30 days old, 90-120 g) and 15 transgenic eGFP ${ }^{+}$C57BL/6 mice (60 days old, $25-30 \mathrm{~g}$ ) were used in this study. All animals were kept under environmentally controlled conditions (12-hour light/dark cycle; $22-24^{\circ} \mathrm{C}$ ) and were given free access to food and water. This study was approved by the Animal Care and Use Committee of Pontifícia Universidade Católica do Rio Grande do Sul. A timeline of the drug administrations, treatments and tests of animals is shown in Table 1 .

\section{Status epilepticus (SE)}

Experimental SE was induced by lithium-pilocarpine injection (127 mg/kg, i.p. and $60 \mathrm{mg} / \mathrm{kg}$, i.p.; respectively) (Cavalheiro et al., 1991; Turski et al., 1983). Animals were treated with $1 \mathrm{mg} / \mathrm{kg}$ methyscopolamine prior to pilocarpine injection to reduce peripheral cholinergic effects. The duration of SE was controlled with diazepam ( $10 \mathrm{mg} / \mathrm{kg}$, i.p.; $90 \mathrm{~min}$ after SE onset). Seizures were scored using the Racine scale (Racine, 1972), and only animals that were scored grade 5 were included in this study. Control animals received saline instead of pilocarpine.

\section{BMMC and fibroblast preparation}

BMMCs were obtained from C57BL/6 mice expressing eGFP, which was used as a reporter of transplanted cells (Okabe et al., 1997). Fresh bone marrow was extracted from humeri, femora and tibiae with a $26 \mathrm{G}$ needle containing heparin (10,000 $\mathrm{U}$ in $50 \mathrm{ml}$ of DPBS). The material was centrifuged at $400 \times g$ for $10 \mathrm{~min}$. The cell pellet was resuspended with Roswell Park Memorial Institute (RPMI-1640) medium and fractionated on a density gradient generated by centrifugation at $400 \times g$ over a Ficoll-Paque solution (Histopaque 11191 Sigma Aldrich, St. Louis, MO). The mononuclear fraction over the Ficoll-Paque layer was collected and washed twice with DPBS. Cell concentrations were determined with a Neubauer-counting chamber, and the number of viable cells was determined by Trypan Blue exclusion. For the detection of surface antigen, BMMCs were incubated with conjugated antibodies

Table 1

Timeline of experimental procedures.

\begin{tabular}{ll}
\hline Day 1 & Lithium administration \\
Day 2 & Pilocarpine-induced SE \\
Days $15-21$ & Video-monitoring of SRS (Pre-T) \\
Day 22 & BMMC, saline or fibroblast administration \\
Day 23 & Nested-PCR (24 h post-transplantation) \\
Days 23-29 & Video-monitoring of SRS (Post-T1) \\
Days 30-37 & Video-monitoring of SRS (Post-T2) \\
Day 36 & Nested-PCR (2 weeks post-transplantation) \\
Days 38-45 & Morris Water Maze task \\
Day 52 & Nested-PCR (1 month post-transplantation) \\
Day 82 & Nested-PCR (2 months post-transplantation) \\
\hline
\end{tabular}

against CD34, CD11b, CD117, CD45 and Sca1. Labeled cells were collected and analyzed using a FACSCalibur cytometer. To ensure a cellular control for BMMC transplantation, we used fibroblasts that were obtained from NIH-3T3 cells line (American Type Culture Collection ATCC no. CRL-1658 ${ }^{\mathrm{TM}}$ Rockville, MD). Fibroblasts were cultured with DMEM medium (Sigma Aldrich, St. Louis, MO) supplemented with $10 \%$ bovine fetal serum, penicillin $(100 \mathrm{U} / \mathrm{ml})$ and streptomycin $(100 \mathrm{U} / \mathrm{mL})$ at $37{ }^{\circ} \mathrm{C}$ in a humid atmosphere containing $5 \% \mathrm{CO}_{2}$. The culture medium was replaced every 3 days, and cells were split whenever they reached $70 \%$ confluence. Cell viability was evaluated by Trypan Blue exclusion.

\section{Transplantation of BMMCs or fibroblasts}

After 7 days of video-monitoring, surviving lithium-pilocarpine animals that showed spontaneous recurrent seizures (SRS) were divided into three groups: Pilo + Saline (lithium-pilocarpine-treated rats receiving saline injection, $n=8$ ); Pilo + BMMC (lithium-pilocarpine-treated rats transplanted with BMMC, $n=8$ ) and Pilo + Fib (lithium-pilocarpine-treated rats transplanted with fibroblasts, $n=7$ ). Control non-epileptic animals were assigned to the following groups: Saline (saline-treated rats receiving saline injection in replacement of both pilocarpine and BMMC, $n=8$ ) and Saline + BMMC (saline-treated rats transplanted with BMMC, $n=8$ ). The BMMC or fibroblast suspension was prepared for transplantation in saline at a concentration of $1 \times 10^{7}$ cells in $200 \mu \mathrm{L}$ total volume. The cells or saline were administered via tail vein injection 22 days after SE. An additional cohort of eight epileptic animals were injected with BMMCs as described above but were sacrificed $24 \mathrm{~h}, 2$ weeks or 1 month after transplantation, and brain samples were collected for PCR. Animals that did not exhibit seizures during the first 7 days of video monitoring were not included in this study.

\section{Monitoring of spontaneous recurrent seizures (SRS)}

Beginning 15 days after SE, the surviving animals were video monitored 12 h/day (6-h light cycle and 6-h dark cycle) for 7 days. This period was called "Pre-transplant" (Pre-T). On the seventh day of monitoring ( 22 days after SE), animals were given BMMCs, fibroblasts or saline. Monitoring was maintained for another 14 days after transplantation. For data analysis, the post-transplant period was divided into 2 sub-periods of 7 days each: "Post-transplant 1" (PostT1) and "Post-transplant 2" (Post-T2). Spontaneous seizures corresponding to grade 5 according to Racine's scale were considered for statistical analysis. The observer was blind to the treatment (Arida et al., 1999).

\section{Training in the spatial version of the Morris water maze (MWM)}

The MWM was used to test spatial memory after BMMC, fibroblast or saline administration (Bonini et al., 2007; Greggio et al., 2011; Morris, 1984). Briefly, training was carried out for five consecutive days. Rats were trained for eight trials a day, during which the platform location remained constant. Each trial consisted of a swim followed by a 30 -s stay on the escape platform. Animals were given $60 \mathrm{~s}$ to find the submerged platform and were guided to it by the experimenter when they were unable to find it. Time spent to find the platform was defined as escape latency. A randomly chosen start position was used in each trial. On day 6, the platform was removed, and long-term spatial memory was evaluated during a probe test. The rats were allowed $60 \mathrm{~s}$ of free swimming. The latency to swim to the location where the platform was previously located, the time spent in the quadrant where the platform was previously located (training quadrant) and the number of crossings over an imaginary annulus centered at that location were measured and used as indicators of memory retention. Swimming velocity was also analyzed. 
EGFP detection using Polymerase Chain Reaction (PCR)

We performed PCR analysis to identify the presence of transplanted BMMCs in the brains of transplanted animals. We used the forward primer 5'-ttgaattcgccaccatggtgagc-3' and the reverse primer $5^{\prime}$ ttgaattcttacttgtacagctcgtcc- $3^{\prime}$ complimentary to an eGFP DNA sequence, and reamplified with the forward primer $5^{\prime}$-gggcacaagctggagtaca- $3^{\prime}$ and the reverse primer 5'-atgttgtggcggatcttga-3' using a nested PCR technique. Animals were sacrificed, and samples were collected $24 \mathrm{~h}$, 2 weeks, and 1 and 2 months after BMMC transplantation. A positive control sample (eGFP ${ }^{+}$DNA extracted from C57BL/6-eGFP mice) and a negative control (without any DNA) were assayed along with experimental samples in every reaction. Amplified products were detected by gel electrophoresis ( $2 \%$ agarose containing ethidium bromide) and visualized under ultraviolet light (Okabe et al., 1997).

\section{Statistical analysis}

Data are presented as means \pm standard deviation (S.D.) or means \pm standard error of the mean (S.E.M.) as indicated in the figure legends. A two-way analysis of variance (ANOVA) followed by the Bonferroni post hoc test was used to analyze SRS frequency and duration. Data obtained in the MWM were analyzed using a two-way ANOVA followed by the Bonferroni post hoc test or a one-way ANOVA followed by the Newman-Keuls post hoc test. Analyses were performed using PrismGraph 5.0 software (Graph-Pad Software, San Diego, CA). A statistical significance level of $\alpha=0.05$ and $p<0.05$ was applied to all tests.

\section{Results}

BMMC transplantation reduces SRS frequency but not duration in chronic epileptic rats

All rats administered with pilocarpine developed SE (grade 5 in Racine's Scale) with a mean latency of $23.24 \pm 7.15$ min. Mortality 7 days after SE was approximately 30\%. Six animals that did not show SRS during the first days of video-monitoring were excluded from the study prior to cell treatment. To analyze whether BMMC reduced the duration and frequency of seizures, we monitored lithium-pilocarpine-treated rats for 21 days and computed the number and duration of behavioral features corresponding to Racine grade 5. We used the difference in SRS frequency and duration at pre- and post-transplant periods to infer whether BMMC promoted functional improvement.

We did not observe significant differences in SRS frequency between groups in the period prior to cell administration (Pilo 12.13 \pm 1.12 , Pilo \pm BMMC $12.25 \pm 1.03$, Pilo + Fib $12.00 \pm 2.00$ ). However, BMMC transplantation reduced seizure frequency in chronic epileptic rats $\left[F_{(2,60)}=\right.$ 6.6, $p=0.0002$, Fig. 1A]. At Post-T1, Pilo + BMMC rats showed fewer seizures $(10.13 \pm 0.83)$ when compared to animals treated with saline $(12.5 \pm 1.19, p<0.01)$ or fibroblasts $(12.14 \pm 2.73, p<0.05)$ (Fig. $1 \mathrm{~A})$. Interestingly, at Post-T2, Pilo + BMMC, rats presented even fewer frequent seizures $(8.50 \pm 0.53)$ when compared to saline $(13 \pm 1.41)$ or fibroblast-treated rats $(13.43 \pm 2.07, p<0.001$ vs. Pilo and vs. Pilo + Fib). Hence, we observed a gradual reduction in seizure frequency as the Pilo + BMMC animals showed less SRS in Post-T2 than in Post-T1. Pilo and Pilo + Fib groups were not significantly different (Fig. 1A), and for the duration of SRS, we did not observe significant differences among any of the groups $\left[F_{(2,60)}=0.25, p=0.9083\right.$, Fig. 1B].

BMMCs reverse the cognitive deficit associated with the lithium-pilocarpine model in the MWM

To evaluate whether BMMCs can reverse the cognitive deficits associated with the lithium-pilocarpine model of epilepsy, we employed a MWM massed training protocol (Bonini et al., 2007;
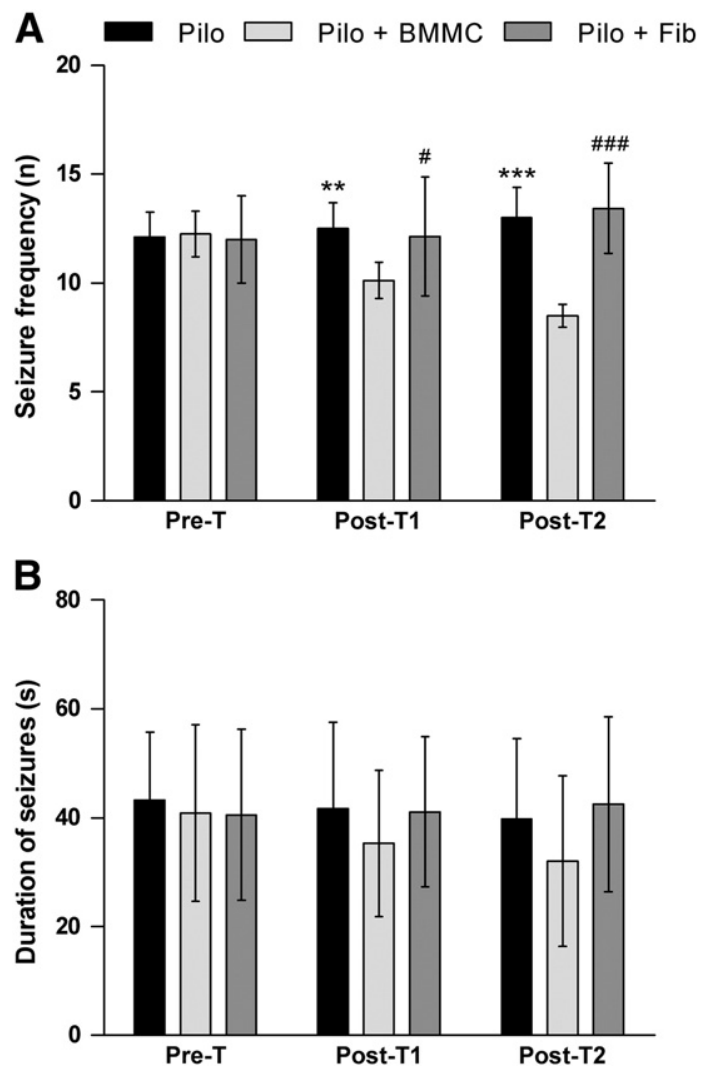

Fig. 1. BMMCs reduce seizure frequency in lithium-pilocarpine-treated rats. (A) Seizure frequency observed for Pilo, Pilo + BMMC and Pilo + Fib groups prior to (Pre-T) and after cell transplantation: post-transplant 1 (Post-T1) and 2 (Post-T2). (B) Seizure duration for Pilo, Pilo + BMMC and Pilo + Fib groups prior to (Pre-T) and after cell transplantation: post-transplant 1 (Post-T1) and 2 (Post-T2). Data are presented as the mean \pm S.D., $\mathrm{n}=8$ per group. ${ }^{* * *} \mathrm{p}<0.001,{ }^{* *} \mathrm{p}<0.01$ vs. Pilo; $\# \mathrm{p}<0.05, \# \# \# \mathrm{p}<0.001$ vs. Pilo + Fib in Bonferroni post hoc test after two-way ANOVA.

Morris, 1984). We observed a significant difference in the learning performance among experimental groups in the 5-day training session $\left[F_{(3,140)}=0.98, p=0.47\right.$, Fig. 2A]. As expected, lithiumpilocarpine-induced epilepsy impaired spatial memory acquisition in the MWM. BMMC administration decreased escape latency in lithium-pilocarpine treated animals. BMMCs did not affect the performance of Saline + BMMC animals because we did not observe any significant difference in these animals compared to controls.

A 60-s probe test in the absence of the escape platform carried out $24 \mathrm{~h}$ after the last training session confirmed that lithium-pilocarpine impairs the acquisition of spatial memory and that BMMCs reverse this effect. Lithium-pilocarpine-treated animals spent less time swimming in the target quadrant (Fig. $2 \mathrm{~B}, p<0.001$ ), crossed the imaginary annulus fewer times (Fig. $2 \mathrm{C}, p<0.001$ ) and displayed significantly longer latencies to swim over the previous location of the platform (Fig. 2D, $p<0.01$ ) when compared to the Saline group. Conversely, during the probe test, Pilo + BMMC rats showed a preference for the training quadrant (Fig. 2B, $p<0.05$ vs. Pilo). Additionally, Pilo + BMMC rats crossed an imaginary annulus centered at the previous location of the escape platform more times than Pilo animals (Fig. 2C, $p<0.01$ ), and they showed significantly shorter latencies to swim over the previous location of the escape platform (Fig. 2D, $p<0.01$ vs. Pilo). In addition, the escape latency observed in lithium-pilocarpine-treated rats transplanted with BMMC was comparable to that of the Saline and Saline + BMMC groups (Fig. 2D). There was no significant difference in swimming speed among the experimental groups (data not shown). Unfortunately, Pilo + Fib 

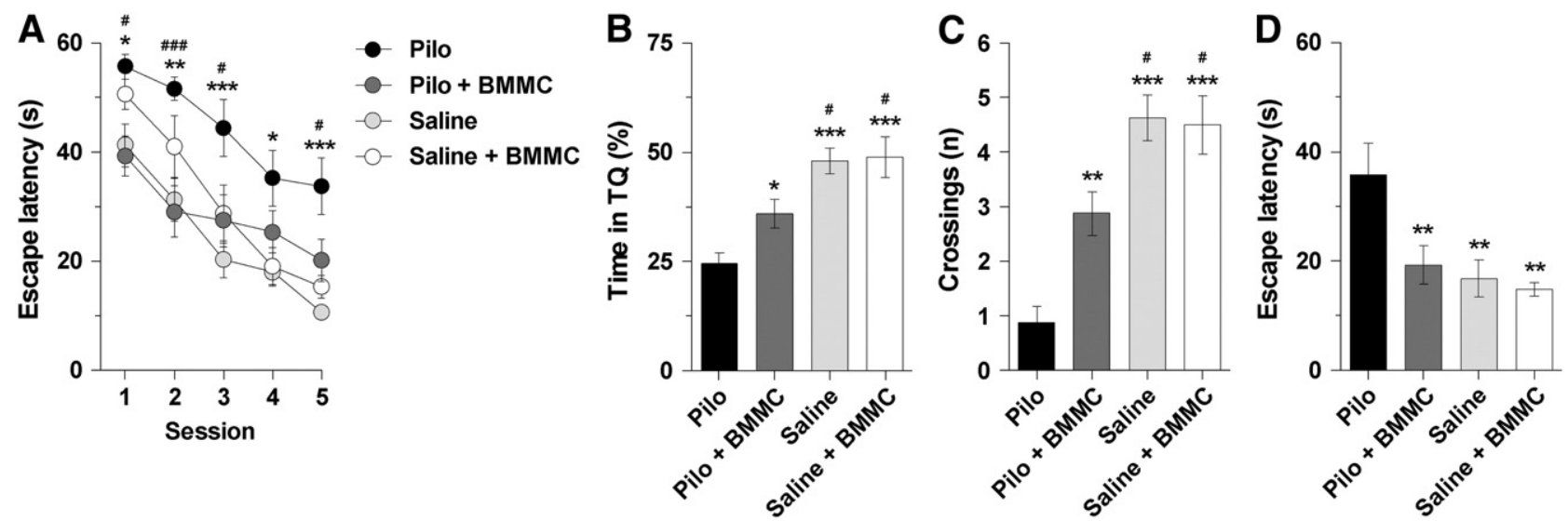

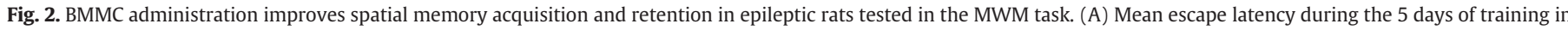

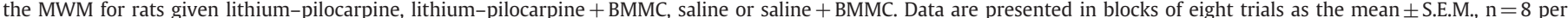

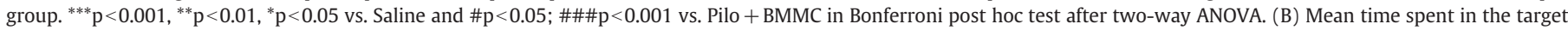

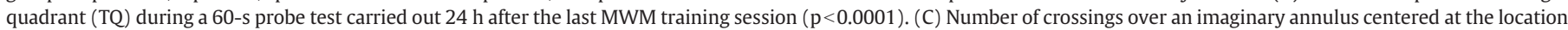

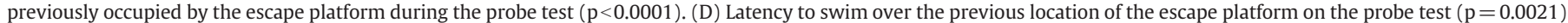

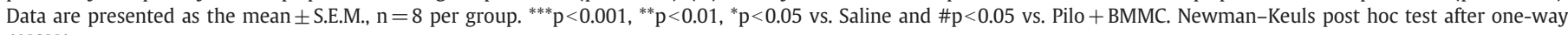
ANOVA.

animals were also trained, but they were not able to complete the MWM task due to the constant occurrence of SRS.

\section{EGFP was detected in samples obtained from the brains of BMMC-transplanted animals}

We employed a nested PCR analysis to verify whether eGFP DNA from BMMCs could be detected in the brains of transplanted animals. This analysis was performed to elucidate whether the observed beneficial behavioral effects were associated with the migration of cells to the injured brain. Amplified eGFP DNA was found in the brain of animals $24 \mathrm{~h}, 2$ weeks and 1 month post-transplantation. At 2 months after transplantation, eGFP was no longer detected in sampled brain tissue (Fig. 3).

\section{Discussion}

In the present study, we demonstrated that BMMC administration to chronic epileptic rats decreases the frequency but not the duration of SRS. We also showed that cell transplantation prevents the learning and memory deterioration due to lithium-pilocarpine induced SE. The positive outcomes observed in our study could be correlated to the presence of transplanted cells into the injured epileptic brain. This is a pioneering study providing behavioral evidence supporting cell-based therapy for chronic epilepsy.

Because seizures are intimately associated with epilepsy, we aimed to verify whether BMMCs reduce the frequency and/or duration of recurrent generalized seizures in chronic epileptic rats. Our results demonstrate that seizures were gradually reduced in Pilo + BMMC rats compared to those receiving pilocarpine alone (Pilo group) or fibroblasts (Pilo + Fib). A number of approaches have been tested using cell therapy in epilepsy models. Ruschenschmidt et al. (2005) have demonstrated that embryonic stem cell-derived neurons display characteristic properties of neurons when transplanted in the hippocampi of chronic epileptic animals. The same grafting technique using striatal precursors, adult neural stem cells or hippocampal stem cells in an acute period of the disease reduced seizure frequency in chronic epilepsy (Hattiangady et al., 2008; Jing et al., 2009; Shen et al., 2010). Choosing a different method of administration, Chu et al. (2004) evaluated the effects of intravenously injected neural stem/

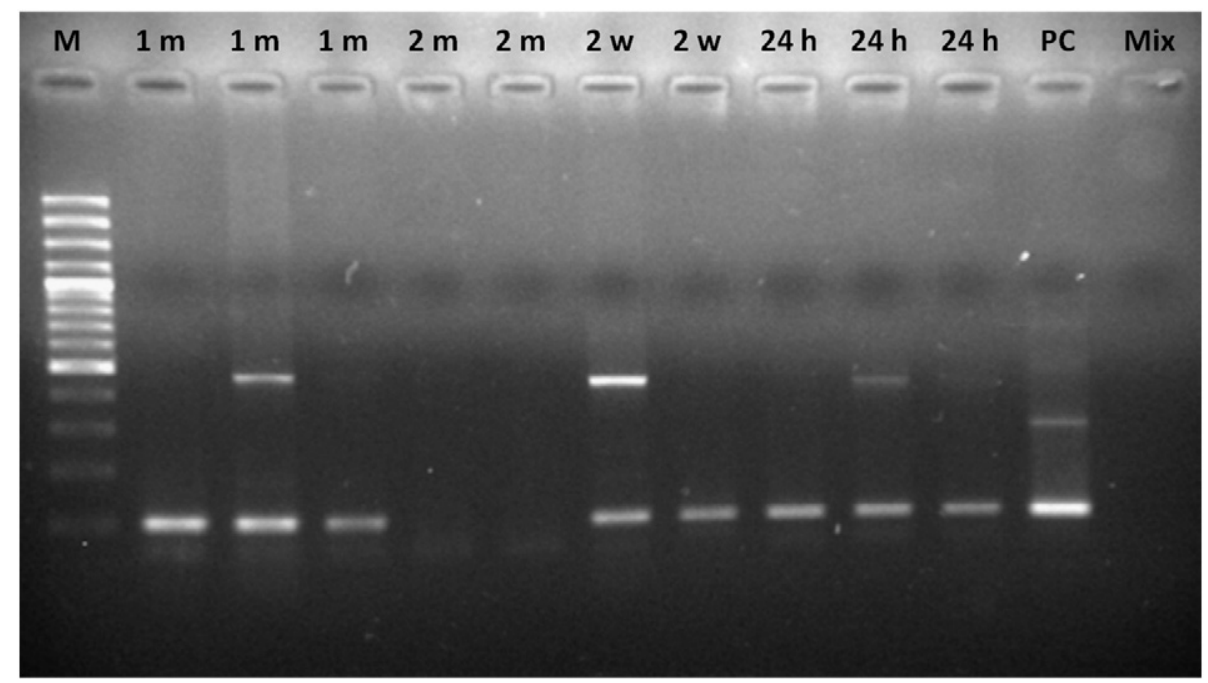

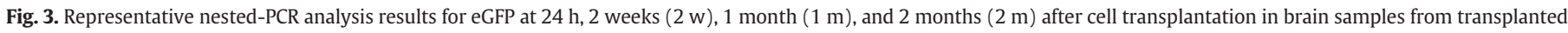

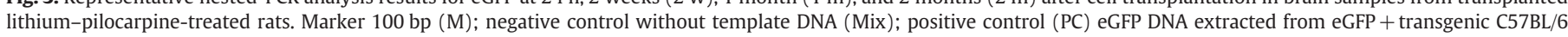
mice. 
progenitor cells on SRS. In that work, cells were also administered during the acute period of epilepsy. Twenty-eight to 35 days later, only $13 \%$ of the animals showed SRS, with a marked reduction in seizure frequency. More recently, Costa-Ferro et al. (2010) showed that BMMCs intravenously injected in rats $24 \mathrm{~h}$ post-SE are able to suppress early SRS, reducing epileptogenesis (Costa-Ferro et al., 2010). In the mentioned study only $25 \%$ of the transplanted animals had SRS 120 days after BMMC administration. In addition, the authors also showed a protective effect on long-term potentiation (LTP). It must be highlighted that in only one of these studies was cell transplantation performed during chronic epilepsy (Ruschenschmidt et al., 2005), and this study did not evaluate seizure frequency.

Compared to the literature, especially concerning the intravenous administration of cells, we observed a less pronounced reduction in SRS frequency in the present study. This could be due to the fact that, in contrast to the above-mentioned works, we administered the cells 22 days after SE, which allowed us to analyze their effect on chronic epilepsy. Considering that transplanted cells could have found very different niches, it was expected that we would observe a less dramatic reduction in SRS frequency. In a chronic epileptic rat, transplanted cells would have to regenerate a more extensive neuronal area to compensate for the cells lost during the course of either SE or SRS. Conversely, in an acute epileptic brain, cells could exert their action by preventing further neuronal death. Therefore, other studies set out to verify the neuroprotective effect of stem cells from different sources and their ability to prevent the development of SRS, suppressing epileptogenesis. In contrast, our purpose was to analyze the potential of BMMCs in healing an established epileptic brain. Our results are relevant to stem cell transplants during the chronic epileptic period. Because most patients that seek medical attention have a seizure history, the chronic epilepsy period would be the most suitable for translational cell therapy-based interventions.

In another set of experiments, we observed that BMMCs improved cognitive deficits in the MWM task. Cognitive deficits are present in experimental epileptic animals and in patients with TLE, probably due to hippocampal cell loss (Detour et al., 2005; Hermann et al., 2006). For this reason, we employed the spatial version of the MWM task to analyze whether BMMCs reverse cognitive deficits associated with epilepsy. It is known that pilocarpine-treated epileptic rats display poor performance on this task (Detour et al., 2005). We observed that epileptic animals that received BMMCs performed better in the MWM, indicating that transplanted cells have a palliative effect on the mnemonic impairment associated with lithium-pilocarpine. To our knowledge, no other studies have used memory tasks to measure functional improvement or preservation after cell therapy in epilepsy. Nonetheless, our results are partially consistent with the data previously obtained by our group, showing that BMMCs are able to preserve LTP, which is an electrophysiological correlate of memory (Costa-Ferro et al., 2010).

Here, we show that EGFP DNA from intravenously injected BMMCs can be found in the epileptic brain $24 \mathrm{~h}, 2$ weeks and 1 month posttransplantation. However, 2 months after the BMMCs administration, EGFP was no longer detected. In a previous study, we showed that the number of cells that enter the epileptic brain after intravenous injection is small. Nonetheless, the cells equally survive for as long as 120 days for either allogenic or xenogenic transplantations (Costa-Ferro et al., 2010). Thus, it is likely that EGFP is undetectable 2 months after transplantation because of the small number of cells that gain access to the brain rather than because of an immunological response against xenotransplanted cells. In addition, it can be assumed that the blood-brain barrier (BBB) could limit the access of an increased number of cells to the injured epileptic brain. However, recent data show that beneficial effects observed after permeation of the BBB do not seem to relate to the grafting of an increased amount of cells - which were only sporadically detected in either animals that received mannitol or not - but rather to other mechanisms such as the up-regulation of neurotrophic factors (Borlongan et al., 2004; Yasuhara et al., 2010).
Our data also show that intravenously injected BMMCs from eGFP transgenic mice enter the brain of epileptic rats, reduce SRS frequency and facilitate spatial learning. However, the mechanisms that underlie these functional improvements remain unclear. The bone marrow is a permanent source of stem cells (Korbling and Estrov, 2003). Several studies have demonstrated that BMMCs grafted in the central nervous system express microglial and neuronal markers (Brazelton et al., 2000; Eglitis and Mezey, 1997; Mezey et al., 2000). In addition, BMMC transdifferentiation into neurons was observed in human tissue (Cogle et al., 2004). However, it is possible that BMMCs could exert their effects by mechanisms other than transdifferentiation. Considering that epilepsy has an important inflammatory component (Vezzani and Granata, 2005), the modulation of this component by stem cells could represent an important aspect in the mechanism of stem cell transplantation (Louboutin et al., 2011; Ohtaki et al., 2008; Park et al., 2009; Pluchino et al., 2005; Schwarting et al., 2008). On the other hand, the transplanted cells could provide the epileptic brain with a number of trophic factors (Borlongan et al., 2004). It has been shown in the hippocampus of epileptic rats that trophic factors such as fibroblast growth factor 2 (FGF-2), brain-derived neurotrophic factor (BDNF) and glial cell-derived neurotrophic factor (GDNF) can reduce epileptogenesis (Eves et al., 2001; Kanter-Schlifke et al., 2007; Rao et al., 2006). Furthermore, growth factors that have been identified in hematopoiesis and angiogenesis - such as erythropoietin (EPO) and granulocyte colony-stimulating growth factor (G-CSF) are currently being re-considered as therapeutic agents in a number of neurological diseases (Chu et al., 2008; Li et al., 2009a; Maurer et al., 2008; Minnerup et al., 2008). Additionally, it must be noted that chronic temporal lobe epilepsy is associated with decreased neurogenesis (Hattiangady et al., 2004), which can contribute to the persistence of seizures and cognitive deficits. Indeed, during chronic epilepsy, the levels of several trophic factors that play a role in neural stem cells proliferation decrease (Shetty et al., 2003). Thus, providing the epileptic brain with a means to recover the process of neurogenesis (e.g. via stem cell administration) might be beneficial in the treatment of epilepsy.

\section{Conclusion}

Our study provides evidence that intravenously administered BMMCs can reduce seizure frequency and ameliorate learning and spatial memory impairments in chronic epileptic rats. Here, we show for the first time that BMMCs have a therapeutic effect on chronic epilepsy and on lost cognitive functions following cell transplantation. Further studies to elucidate the mechanisms by which transplanted cells exert their effects are needed. Nonetheless, the positive behavioral effects we observed represent a step toward BMMC transplantation becoming an option for the management of chronic epilepsy.

\section{Conflict of interest statement}

The authors certify that there is no conflict of interest with any financial organization regarding the material discussed in the manuscript.

\section{Acknowledgments}

This work was supported by research grants from the National Council of Scientific and Technological Development (CNPq) through the Department of Science and Technology of the Ministry of Health (Decit - Ministério da Saúde), Pandurata SA, Gama e Souza and the Paraná University Foundation (FUNPAR). J.C. da Costa, M. Cammarota and D.C. Machado are researchers of the CNPq. G.T. Venturin and S. Greggio are recipients of PhD degree fellowships from Coordination for the Improvement of Higher Education Personnel (CAPES) and $\mathrm{CNPq}$ (Brazil). The authors wish to thank professors Ricardo Ribeiro Santos and Milena Soares, who provided the eGFP transgenic mice, 
and the helpful assistance of Simone Denise Salamoni and Daniela Souza de Abreu.

\section{References}

Arida RM, Scorza FA, Peres CA, Cavalheiro EA. The course of untreated seizures in the pilocarpine model of epilepsy. Epilepsy Res 1999;34(2-3):99-107.

Babb TL, Kupfer WR, Pretorius JK, Crandall PH, Levesque MF. Synaptic reorganization by mossy fibers in human epileptic fascia dentata. Neuroscience 1991;42(2):351-63.

Blumcke I, Beck H, Scheffler B, Hof PR, Morrison JH, Wolf HK, et al. Altered distribution of the alpha-amino-3-hydroxy-5-methyl-4-isoxazole propionate receptor subunit GluR2(4) and the N-methyl-D-aspartate receptor subunit NMDAR1 in the hippocampus of patients with temporal lobe epilepsy. Acta Neuropathol 1996;92 (6):576-87.

Blumcke I, Beck H, Lie AA, Wiestler OD. Molecular neuropathology of human mesial temporal lobe epilepsy. Epilepsy Res 1999;36(2-3):205-23.

Bonini JS, Da Silva WC, Bevilaqua LR, Medina JH, Izquierdo I, Cammarota M. On the participation of hippocampal PKC in acquisition, consolidation and reconsolidation of spatial memory. Neuroscience 2007;147(1):37-45.

Borlongan CV, Hadman M, Sanberg CD, Sanberg PR. Central nervous system entry of peripherally injected umbilical cord blood cells is not required for neuroprotection in stroke. Stroke 2004;35(10):2385-9.

Brazelton TR, Rossi FM, Keshet GI, Blau HM. From marrow to brain: expression of neuronal phenotypes in adult mice. Science 2000;290(5497):1775-9.

Carpentino JE, Hartman NW, Grabel LB, Naegele JR. Region-specific differentiation of embryonic stem cell-derived neural progenitor transplants into the adult mouse hippocampus following seizures. J Neurosci Res 2008;86(3):512-24.

Cavalheiro EA, Leite JP, Bortolotto ZA, Turski WA, Ikonomidou C, Turski L. Long-term effects of pilocarpine in rats: structural damage of the brain triggers kindling and spontaneous recurrent seizures. Epilepsia 1991;32(6):778-82.

Chu K, Kim M, Jung KH, Jeon D, Lee ST, Kim J, et al. Human neural stem cell transplantation reduces spontaneous recurrent seizures following pilocarpineinduced status epilepticus in adult rats. Brain Res 2004;1023(2):213-21.

Chu K, Jung KH, Lee ST, Kim JH, Kang KM, Kim HK, et al. Erythropoietin reduces epileptogenic processes following status epilepticus. Epilepsia 2008;49(10): 1723-32.

Cogle CR, Yachnis AT, Laywell ED, Zander DS, Wingard JR, Steindler DA, et al. Bone marrow transdifferentiation in brain after transplantation: a retrospective study. Lancet 2004;363(9419):1432-7.

Costa-Ferro ZS, Vitola AS, Pedroso MF, Cunha FB, Xavier LL, Machado DC, et al. Prevention of seizures and reorganization of hippocampal functions by transplantation of bone marrow cells in the acute phase of experimental epilepsy. Seizure 2010;19(2):84-92.

Detour J, Schroeder H, Desor D, Nehlig A. A 5-month period of epilepsy impairs spatial memory, decreases anxiety, but spares object recognition in the lithiumpilocarpine model in adult rats. Epilepsia 2005;46(4):499-508.

Eglitis MA, Mezey E. Hematopoietic cells differentiate into both microglia and macroglia in the brains of adult mice. Proc Natl Acad Sci U S A 1997:94(8):4080-5.

Engel Jr J. A proposed diagnostic scheme for people with epileptic seizures and with epilepsy: report of the ILAE Task Force on Classification and Terminology. Epilepsia 2001;42(6):796-803.

Eves EM, Skoczylas C, Yoshida K, Alnemri ES, Rosner MR. FGF induces a switch in death receptor pathways in neuronal cells. J Neurosci 2001;21(14):4996-5006.

Gernert M, Thompson KW, Loscher W, Tobin AJ. Genetically engineered GABAproducing cells demonstrate anticonvulsant effects and long-term transgene expression when transplanted into the central piriform cortex of rats. Exp Neurol 2002;176(1):183-92.

Greggio B, et al. NAP prevents acute cerebral oxidative stress and protects against longterm brain injury and cognitive impairment in a model of neonatal hypoxiaischemia. Neurobiol Dis 2011. doi:10.1016/j.nbd.2011.06.018.

Hattiangady B, Rao MS, Shetty AK. Chronic temporal lobe epilepsy is associated with severely declined dentate neurogenesis in the adult hippocampus. Neurobiol Dis 2004;17(3):473-90.

Hattiangady B, Rao MS, Shetty AK. Grafting of striatal precursor cells into hippocampus shortly after status epilepticus restrains chronic temporal lobe epilepsy. Exp Neurol 2008;212(2):468-81.

Hermann BP, Seidenberg M, Bell B. The neurodevelopmental impact of childhood onset temporal lobe epilepsy on brain structure and function and the risk of progressive cognitive effects. Prog Brain Res 2002;135:429-38.

Hermann BP, Seidenberg M, Dow C, Jones J, Rutecki P, Bhattacharya A, et al. Cognitive prognosis in chronic temporal lobe epilepsy. Ann Neurol 2006;60(1):80-7.

Huber A, Padrun V, Deglon N, Aebischer P, Mohler H, Boison D. Grafts of adenosinereleasing cells suppress seizures in kindling epilepsy. Proc Natl Acad Sci U S A 2001;98(13):7611-6.

Jing M, Shingo T, Yasuhara T, Kondo A, Morimoto T, Wang F, et al. The combined therapy of intrahippocampal transplantation of adult neural stem cells and intraventricular erythropoietin-infusion ameliorates spontaneous recurrent seizures by suppression of abnormal mossy fiber sprouting. Brain Res 2009;1295:203-17.
Kanter-Schlifke I, Georgievska B, Kirik D, Kokaia M. Seizure suppression by GDNF gene therapy in animal models of epilepsy. Mol Ther 2007;15(6):1106-13.

Korbling M, Estrov Z. Adult stem cells for tissue repair - a new therapeutic concept? N Engl J Med 2003;349(6):570-82.

Li L, Jiang Q, Ding G, Zhang L, Zhang ZG, Li Q, et al. MRI identification of white matter reorganization enhanced by erythropoietin treatment in a rat model of focal ischemia. Stroke 2009a;40(3):936-41.

Li T, Ren G, Kaplan DL, Boison D. Human mesenchymal stem cell grafts engineered to release adenosine reduce chronic seizures in a mouse model of CA3-selective epileptogenesis. Epilepsy Res 2009b;84(2-3):238-41.

Loscher W. Current status and future directions in the pharmacotherapy of epilepsy. Trends Pharmacol Sci 2002;23(3):113-8.

Louboutin JP, Chekmasova A, Marusich E, Agrawal L, Strayer DS. Role of CCR5 and its ligands in the control of vascular inflammation and leukocyte recruitment required for acute excitotoxic seizure induction and neural damage. FASEB J 2011;25(2): 737-53.

Maurer MH, Schabitz WR, Schneider A. Old friends in new constellations - the hematopoetic growth factors G-CSF, GM-CSF, and EPO for the treatment of neurological diseases. Curr Med Chem 2008;15(14):1407-11.

Mezey E, Chandross KJ, Harta G, Maki RA, McKercher SR. Turning blood into brain: cells bearing neuronal antigens generated in vivo from bone marrow. Science 2000;290 (5497):1779-82.

Minnerup J, Heidrich J, Wellmann J, Rogalewski A, Schneider A, Schabitz WR. Metaanalysis of the efficacy of granulocyte-colony stimulating factor in animal models of focal cerebral ischemia. Stroke 2008;39(6):1855-61.

Morris R. Developments of a water-maze procedure for studying spatial learning in the rat. J Neurosci Methods 1984;11(1):47-60.

Ohtaki H, Ylostalo JH, Foraker JE, Robinson AP, Reger RL, Shioda S, et al. Stem/progenitor cells from bone marrow decrease neuronal death in global ischemia by modulation of inflammatory/immune responses. Proc Natl Acad Sci U S A 2008;105(38): 14638-43.

Okabe M, Ikawa M, Kominami K, Nakanishi T, Nishimune Y. 'Green mice' as a source of ubiquitous green cells. FEBS Lett 1997;407(3):313-9.

Oyegbile TO, Dow C, Jones J, Bell B, Rutecki P, Sheth R, et al. The nature and course of neuropsychological morbidity in chronic temporal lobe epilepsy. Neurology 2004;62(10):1736-42.

Oyegbile TO, Bhattacharya A, Seidenberg M, Hermann BP. Quantitative MRI biomarkers of cognitive morbidity in temporal lobe epilepsy. Epilepsia 2006;47(1):143-52.

Park DH, Eve DJ, Musso III J, Klasko SK, Cruz E, Borlongan CV, et al. Inflammation and stem cell migration to the injured brain in higher organisms. Stem Cells Dev 2009;18(5):693-702.

Pluchino S, Zanotti L, Rossi B, Brambilla E, Ottoboni L, Salani G, et al. Neurospherederived multipotent precursors promote neuroprotection by an immunomodulatory mechanism. Nature 2005;436(7048):266-71.

Racine RJ. Modification of seizure activity by electrical stimulation. II. Motor seizure. Electroencephalogr Clin Neurophysiol 1972;32(3):281-94.

Rao MS, Hattiangady B, Shetty AK. Fetal hippocampal CA3 cell grafts enriched with FGF2 and BDNF exhibit robust long-term survival and integration and suppress aberrant mossy fiber sprouting in the injured middle-aged hippocampus Neurobiol Dis 2006;21(2):276-90.

Ruschenschmidt C, Koch PG, Brustle O, Beck H. Functional properties of ES cell-derived neurons engrafted into the hippocampus of adult normal and chronically epileptic rats. Epilepsia 2005;46(Suppl. 5):174-83.

Sander JW, Shorvon SD. Epidemiology of the epilepsies. J Neurol Neurosurg Psychiatry 1996;61(5):433-43.

Schwarting S, Litwak S, Hao W, Bahr M, Weise J, Neumann H. Hematopoietic stem cells reduce postischemic inflammation and ameliorate ischemic brain injury. Stroke 2008;39(10):2867-75

Shen H, Liu L, Huo Z, Lin Z. Hippocampal stem cell grafting-mediated recovery of injured hippocampus in the rat model of temporal lobe epilepsy. Int J Neurosci 2010;120 (10):647-54.

Shetty AK, Zaman V, Shetty GA. Hippocampal neurotrophin levels in a kainate model of temporal lobe epilepsy: a lack of correlation between brain-derived neurotrophic factor content and progression of aberrant dentate mossy fiber sprouting.J Neurochem 2003;87(1):147-59.

Terada N, Hamazaki T, Oka M, Hoki M, Mastalerz DM, Nakano Y, et al. Bone marrow cells adopt the phenotype of other cells by spontaneous cell fusion. Nature 2002;416 (6880):542-5.

Turski WA, Cavalheiro EA, Schwarz M, Czuczwar SJ, Kleinrok Z, Turski L. Limbic seizures produced by pilocarpine in rats: behavioural, electroencephalographic and neuropathological study. Behav Brain Res 1983;9(3):315-35.

Vezzani A, Granata T. Brain inflammation in epilepsy: experimental and clinical evidence. Epilepsia 2005;46(11):1724-43.

Yasuhara T, Hara K, Maki M, Xu L, Yu G, Ali MM, et al. Mannitol facilitates neurotrophic factor up-regulation and behavioural recovery in neonatal hypoxic-ischaemic rats with human umbilical cord blood grafts. J Cell Mol Med 2010;14(4):914-21.

Zaman V, Turner DA, Shetty AK. Survival of grafted fetal neural cells in kainic acid lesioned CA3 region of adult hippocampus depends upon cell specificity. Exp Neurol 2000;161(2):535-61. 